\title{
Remote Sensing based Land Use/Land Cover Change Detection: A Case Study of East Twente, Netherlands
}

\author{
Solomon Mulat* \\ Ethiopian Environment and Forest Research Institute, Ethiopia
}

Submission: March 02, 2020;Published: March 12, 2020

*Corresponding author: Solomon Mulat, Ethiopian Environment and Forest Research Institute, Ethiopia

\section{Abstract}

Land use land cover change analysis has become an important element in the development of strategies for natural and environmental resource management. The main aim of this case study was to demonstrate the land use land cover changes that happened between 2002 and 2010 in the eastern Twente, the Netherlands. The study used Spot and Landsat TM images for the study period of 2002 and 2010 respectively. A Pixel-based supervised image classification technique was used for classification of images. Post classification technique was implemented to analyze the changes occurred between the different land cover types over the study period. The result of the post classification comparison method showed that the major change consisted of agriculture and nature conservation areas changed into built up areas. The result demonstrated that a high reduction in conservation and agriculture area coverage with a reduction percentage of $26.12 \%$ and $16.62 \%$ have happened between the study periods respectively. On the other hand, the built-up area cover has increased by $60.48 \%$ between the year 2002 and 2010 study periods. This study informs the need to tackle the expansion of residential areas through careful spatial planning and design future appropriate land management options.

Keywords: Land use; Change detection; Remote sensing; Land cover

\section{Introduction}

Land use land cover changes have an impact on the composition of the atmosphere which results in the change of climate and weather conditions at the local and global levels [1]. It has become an important element in the development of strategies for natural and environmental resource management [2]. It also affects biological diversity, change ecosystem services, soil erosions and results in natural disasters [3]. The land use land cover changes are mainly triggered by natural disasters and human activities [4]. This implies that it needs attention to monitoring of the earth's resources for sustainable utilization and management of the resources. Land use land cover changes analysis provides information to understand the complex causes and interactions among the earth's resources at the local and global levels [5].

Because of the higher pressure on natural resource utilization in the world, land use and land cover change detection has become a central point in the current strategies for managing natural resources and monitoring environmental changes [6]. These changes amend the availability of different resources including soil, vegetation, water, animal feed and others. Therefore, land use and cover changes could lead to a decreased availability of different resources and services for human, livestock, agricultural production and damage to the environment as well
[7]. Currently, the demand for land in the Netherlands becomes higher due to the expansion of residential and industrial areas in the country. However, food production and natural resource conservation also require land area, and this needs careful planning for sustainable utilization of the resources in the country.

Land use land cover change analysis studies focused on a specific location has been proved to be important for designing sustainable management approaches and decision-making process related to the use and management of the resources $[8,9]$. Remote sensing technologies have been played an important role in land use land cover change detection since its shows the spatial patterns of the dynamics of the land covers types over a large area $[10,11]$. The availability of remote sensing data in digital format has attracted researchers to use it in a wide range of applications. Thus, remote sensing has become an important data for tracking changes in land use land cover types over a long period of time because of its continuous spatial and temporal coverage [12,13].

For effective resource planning and sustainable utilization in the future, land use land cover change detection by incorporating new approaches and taking the modern advanced technology of GIS and earth observation are needed for a better understanding of the evolving process through time [14]. Therefore, this study aimed to detect the land use land cover changes evolve from 2002 to 2010 by giving a special emphasis on areas changed from 
agriculture and nature conservation to build up areas in the study area.

\section{Material and Methods}

\section{Study area}

The study was conducted in Twente, the Netherlands, which is geographically situated on in the province of Overijssel within $52^{\circ} 05^{\prime}$ to $52^{\circ} 27^{\prime} \mathrm{N}$ and $6^{\circ} 05^{\prime}$ to $7^{\circ} 00^{\prime} \mathrm{E}$. The area of the region is approximately $1374 \mathrm{~km}^{2}$. Twente comprises fourteen municipalities. This study focused on the eastern part of Twente.
The area has a temperate climate characterized by mild winters and cold summers. The average temperature varies between $2.2^{\circ} \mathrm{C}$ in winter to $16.6^{\circ} \mathrm{C}$ in the summer season. The average annual rainfall of the area reaches to $916.5 \mathrm{~mm}$ per year. The region is predominantly flat with low lying terrain and covered with mixed oak forests, heath, grasses and crops. The region is dominated by agriculture practice which includes daily farming, livestock production and arable farming. The arable farming in the region is mainly used corn production which is a very demanding crop in the study area [15].

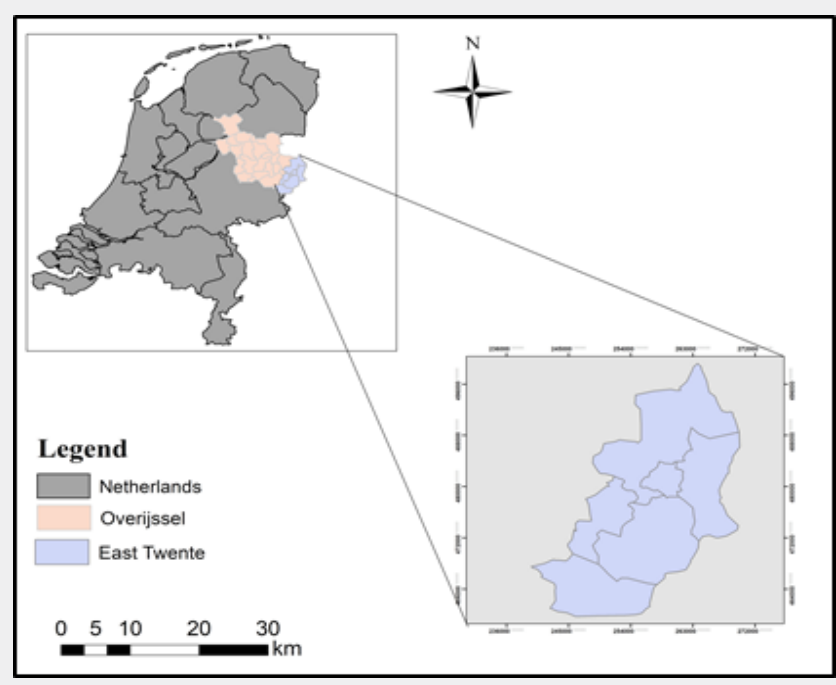

Figure 1: Location of the study area.

\section{Datasets}

In this study, various data sources were used for change detection analysis. Landsat and Spot images were the main data source for image classification and change detection analysis. Besides, auxiliary data such as field data and shapefile data of the study area were used in the analysis. The available dataset was organized properly and made ready for analysis. The Landsat image was converted to the same coordinate system (i.e. Dutch coordinate system) and the Spot image was georeferenced by using the topographic maps and converted to the Dutch coordinate system.

\section{Methods}

\section{Image classification}

ERDAS IMAGINE 2015 software package was used for image processing and classification of the image. Pixel-based supervised maximum likelihood classification method was used to classify images of the year 2002 and 2010 separately. Images of each study years were classified independently. The classification has been done by assigning the different spectral signatures from the satellite image to the different land use land cover classes. Different band combinations were used to identify the different land use land cover types since the image shows a different color in different band combinations. The supervised image classification was supplemented with visual interpretation to improve classification accuracy and reduce misclassification. The result of the supervised classification method provided a thematic raster layer of the different land use land cover classes. Spot and Landsat satellite images for the years 2002 and 2010 from the study area were used for classification. The image was classified into three main land use classes (i.e. built up areas, agricultural and nature conservation areas) for easier change detection comparison. Then, the classified Spot image has been resampled to the same cell size of the Landsat image for further processing and compared the classified images in each other. The accuracy assessment was done for both classified images of Landsat and Spot image. A total of 84 and 92 GPS points were used for classification and validation of the classified image of Spot and Landsat image respectively.

\section{Post classification analysis}

To analyze the land use land cover changes occurred between the years 2002 to 2010, the post classification detection technique was employed. The post-classification technique was selected since it reduces the impact of atmospheric variation, environmental differences and sensor difference between multitemporal images [16]. The image of the different years was classified separately. The post classification change detection 
was done by using the ERDAS Matrix union function. The classified images of the years 2002 and 2010 were compared. The comparison was performed by computing the image value of the years 2002 with the corresponding value of the year 2010 image. The result summarized in the form of a table that shows the overall changes per hectare per each land use land cover class. The positive value indicates an increase in the area of the land use land cover whereas the negative values indicate a decrease in the area of the land use land cover class in the study period.

\section{Result and Discussion}

\section{Classification accuracy assessment}

Accuracy assessment of the classified image has been performed to evaluate to what extent the classified image matched with the reality on the ground. The accuracy assessment has been done for both classified images. The overall accuracy for the year 2002 and 2010 were $76.5 \%$ and $65.2 \%$ using three land use land cover classes. Confusions among the different land use land cover types were observed during the classification of the image. The confusion among the land use land cover types reduced the classification accuracy of the images. High confusion among land use land cover types and lower classification accuracy was observed in the Landsat image. This confusion and lower classification accuracy were associated with the lower spatial resolution of the Landsat image used in the study [11,17]. The area covered by each class also calculated and presented as bellow (Table 1).

\section{Land covers change detection}

A total of three major land use land cover types were identified and extracted for the years 2002 and 2010 of the study area (Figure 2). At the initial year of the study period (2002), Nature conservation areas was the dominant land use land cover type that accounts for $45.30 \%$ followed by agricultural $(27.57 \%)$ and built-up areas $(27.57 \%)$ (Table 1$)$. The result of the land cover change detection showed that most of the lands (i.e. agricultural and nature conservation areas) are changed into built up areas. However, there is a little change from agricultural to nature conservation areas in the region. The red colors in Figure 3 in the land cover map showed the negative changes that occurred in the region which leads the regions in a serious shortage of land for agricultural production as well as nature conservation purpose Figure 2. The area coverage for each land use class for the year 2002 and 2010 are presented as follows in (Table 1).

Table 1: Summaries of area of the main land use/land covers in the study area for the year 2002 and 2010.

\begin{tabular}{|c|c|c|c|c|}
\hline \multirow{2}{*}{ LULC Types } & \multicolumn{2}{|c|}{2002} & \multicolumn{2}{|c|}{$\mathbf{2 0 1 0}$} \\
\cline { 2 - 5 } & Area (Ha) & (\%) & Area (Ha) & (\%) \\
\hline $\begin{array}{c}\text { Conservation } \\
\text { Area }\end{array}$ & $27,407.33$ & 45.3 & $20,249.36$ & 33.47 \\
\hline $\begin{array}{c}\text { Agricultural } \\
\text { Land }\end{array}$ & $16,677.89$ & 27.57 & $13,906.25$ & 22.98 \\
\hline Built-Up Area & $16,416.80$ & 27.13 & $26,346.41$ & 43.55 \\
\hline
\end{tabular}

Table 1, along with Figure 2, summarizes the trends of the identified land use land cover types from 2002 to 2010 with the percentage share of each land cover class. The trend of land use land cover changes were observed for all land use land cover types in 2010. By the end of the study period, 2010, Built-Up area was the dominant land cover which accounts $43.55 \%$ followed by Conservation area (33.47\%) and Agricultural Land (22.98\%)

\section{(Table 1).}

Moreover, Table 2 along with Figure 3, demonstrated the pattern of the land use land cover dynamics during the study period of 2002 and 2010. The result of the study demonstrated that there was a change in land use land cover types in both positive and negative directions. As it has seen in Table 2, the Built-up area has shown an increasing trend with $60.48 \%$ between the study periods of 2002- 2010 in the study area. However, conservation area and agriculture has shown a declined trend with a rate of $26.12 \%$ and $16.62 \%$ respectively with the study period (Table 2 ). Both Conservation and Agricultural land has showed a rapid reduction trend with different rate of change over the study period.

Table 2: The main LULC changes from 2002 to 2010 in (ha) and percentage of LULC changes between the two periods.

\begin{tabular}{|c|c|c|}
\hline \multirow{2}{*}{ LULC Types } & \multicolumn{2}{|c|}{ 2002-2010 } \\
\cline { 2 - 3 } & Area (Ha) & (\%) \\
\hline Conservation Area & $-7,157.97$ & -26.12 \\
\hline Agricultural Land & $-2,771.64$ & -16.62 \\
\hline Built-Up Area & $9,929.61$ & 60.48 \\
\hline
\end{tabular}

The change result of the study showed an increase at the expansion of built-up areas at the expense of other land use land cover types. The total built-up area converted between the study periods covered 9,929.61ha which accounts for $60.48 \%$.

\section{Discussion}

The spatial distribution of land use and its patterns of change are prerequisite to design and develop effective and efficient land use policies related to the use and management of the resources. The study utilized remote sensing data available for the study period to describe the pattern of the land use land cover dynamics in the eastern Twente, the Netherlands. The result of the study provided information on the spatial distribution and patterns of changes in the different land use land cover types within the study period. The result of the study showed that conservation and agricultural areas were highly converted to Built-Up area. The reduction of these resources contributes to the expansion of built-up areas. The finding of the study revealed that BuiltUp area has shown a rapid increment between 2002 and 2010 with the expenses of the other land use land cover types in the area with area coverage of $16,416.80$ ha in 2002 to $26,346.41$ ha in 2010. This indicated that there is a very high population increment that demands areas for a residential area in the study area. The rapid expansion of urban areas within the study period results in ecological and environmental problems associated with unplanned urban area growth and development. Such 
kind of changes could have a negative impact on the use of the resources in the area, and lead to the reduction of productivity. The reduction of agricultural lands due to the expansion of urban areas is a common phenomenon throughout the world. For instance, the study of [18] revealed that the built-up area has shown an increment of $17 \%$ between the study period 1997 and 2008. Expansion of urban areas cannot be stopped entirely but significantly slow down compared to the non-restricted areas [19].

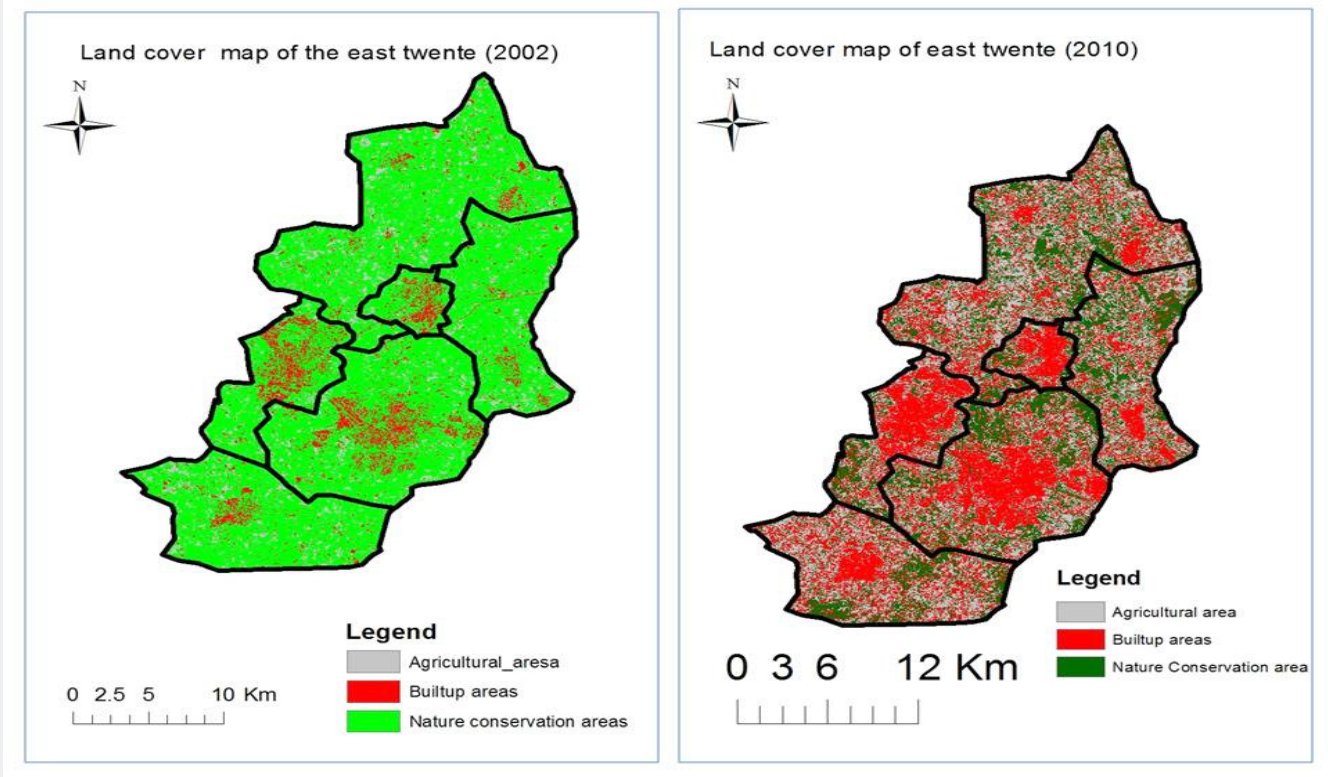

Figure 2: Land cover class maps for using three main land use land cover classes.
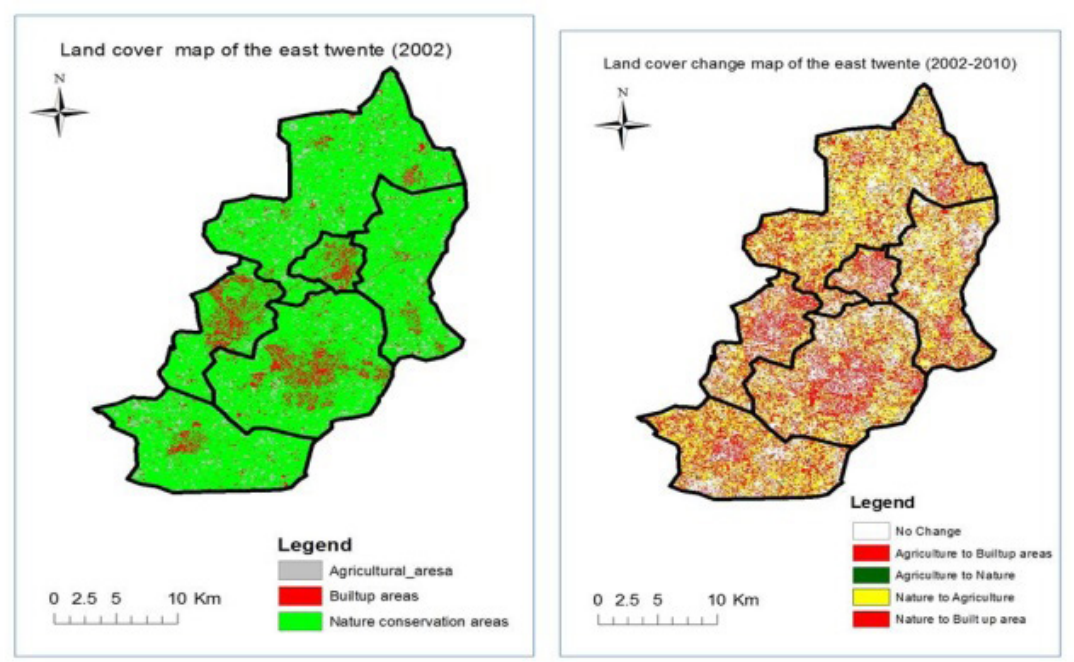

Figure 3: Map showing the main Land use land cover changes between 2002 and 2010.

Eastern Twente has experienced rapid dynamics of land use land cover between the specified study periods. The dynamics of such land use land cover implies for sustainable resource management. The rapid conversion of natural and agricultural areas into urban areas can negatively alter the potential of the use of the area. Unless properly managed these changes, it will lead to environmental and ecological degradation such as loss of agricultural land, reduced green areas and increase land fragmentation [20]. The rapid expansion of built-up area is a challenge for city planners since the growth of urban areas outpaces the planning process as well as the development of infrastructure [20]. 


\section{Conclusion}

Land use and land cover change detection is the fundamental point in the planning of sustainable management and utilization strategies for managing natural resources and monitoring environmental changes as a whole. The result of change detection revealed that most of the land use in the study is changed to builtup areas which include industrial areas in the region. As a result, the demand for land for agricultural production in the study area becomes a serious issue shortly and the environmental condition as well. Therefore, understanding and knowing the evolving process of land use land cover changes are a central point for sustainable planning and need consideration in the future. The finding of this study provided information to policymakers to prevent the unsustain-able expansion of urban areas rather than attempts to slow down its growth. However, the remote sensing approach provides information only on the dynamics of the different land use land cover types over time but does not show information about the driving forces behind the conversion of these resources. Further investigation is, therefore, needed to find the different driving forces of change that help to design and look for alternative solutions for future development plans and strategies.

\section{Acknowledgement}

The author would like to thank the anonymous reviewers who gave constructive comments and suggestions that helped to improve this manuscript.

\section{References}

1. Pielke RA, Marland G, Betts RA, Chase TN, Eastman JL, et al. (2013) The influence of land-use change and landscape dynamics on the climate system: Relevance to climate-change policy beyond the radiative effect of greenhouse gases. Capturing Carbon and Conserving Biodiversity: The Market Approach, pp. 157-172.

2. Rawat JS, Biswas V, Kumar M (2013) Changes in land use/cover using geospatial techniques: A case study of Ramnagar town area, district Nainital, Uttarakhand, India. Egyptian Journal of Remote Sensing and Space Science 16(1): 111-117.

3. Mas JF, Velázquez A, Díaz-Gallegos JR, Mayorga-Saucedo R, Alcántara C, et al. (2004) Assessing land use/cover changes: A nationwide multidate spatial database for Mexico. International Journal of Applied Earth Observation and Geoinformation 5(4): 249-261.

4. Xiaopu W, Tang Z, Cui H, Fang J (2007) Land cover dynamics of different topographic conditions in Beijing, China. Frontiers of Biology in China 2(4): 463-473.

5. Giri C, Zhu Z, Reed B (2005) A comparative analysis of the Global Land Cover 2000 and MODIS land cover data sets. Remote Sensing of Environment 94(1): 123-132.
6. Setiawan Y, Yoshino K (2012) Change detection in land-use and land-cover dynamics at a regional scale from modis time-series imagery. ISPRS Annals of the Photogrammetry, Remote Sensing and Spatial Information Sciences 7: 243-248.

7. Raini JA (2009) Impact of land use changes on water resources and biodiversity of Lake Nakuru catchment basin, Kenya. African Journal of Ecology 47(S1): 39-45.

8. Lunetta RS, Knight JF, Ediriwickrema J, Lyon JG, Worthy LD (2006) Land-cover change detection using multi-temporal MODIS NDVI data. Remote Sensing of Environment 105(2): 142-154.

9. Xiuqin W, Cai Y, Zhou T (2011) Effects of land use/land cover changes on rocky desertification-A case study of a small karst catchment in southwestern China. Energy Procedia 5: 1-5.

10. Singh, P., Thakur, J. K., Kumar, S., \& Singh, U. C. (2012). Assessment of Land Use/Land Cover Using Geospatial Techniques in a Semi-arid Region of Madhya Pradesh, India. In: Thakur JK (Ed.), Geospatial Techniques for Managing Environmental Resources. Dordrecht, Springer, the Netherland/New York, NY, USA.

11. Lillesand TM, Kiefer RW (1979) Remote sensing and image interpretation. Remote Sensing and Image Interpretation. The Geographical Journal 146(3): 448-449.

12. Fan F, Weng Q Wang Y (2007) Land use and land cover change in Guangzhou, China, from 1998 to 2003, based on Landsat TM /ETM+ imagery. Sensors 7(7): 1323-1342.

13. Weng $Q$ (2002) Land use change analysis in the Zhujiang Delta of China using satellite remote sensing, GIS and stochastic modelling. Journal of Environmental Management 64(3): 273-284.

14. Were K, Dick ØB, Singh BR (2014) Exploring the geophysical and socio-economic determinants of land cover changes in Eastern Mau forest reserve and Lake Nakuru drainage basin, Kenya. GeoJournal 79: 775-790.

15. Huitema D (2002) Case Study 2: Regge River Basin. EUWARENESS Project. University of Twente. The, 54.

16. Lu D, Mausel P, Brondízio E, Moran E (2004) Change detection techniques. International Journal of Remote Sensing 25(12): 2365-2401.

17. Dessie G, Kleman J (2007) Pattern and Magnitude of Deforestation in the South Central Rift Valley Region of Ethiopia. Mountain Research and Development 27(2): 162-168.

18. Mohan M, Pathan SK, Narendrareddy K, Kandya A, Pandey S (2011) Dynamics of Urbanization and Its Impact on Land-Use/Land-Cover: A Case Study of Megacity Delhi. Journal of Environmental Protection, 02(09): 1274-1283.

19. Belay Tegene (2002) Land-Cover/Land-Use Changes in the Derekolli Catchment of the South Welo Zone of Amhara Region, Ethiopia. Eastern Africa Social Science Research Review 18(1): 1-20.

20. Koomen E, Dekkers J, van Dijk T (2008) Open-space preservation in the Netherlands: Planning, practice and prospects. Land Use Policy. 
Your next submission with Juniper Publishers will reach you the below assets

- Quality Editorial service

- Swift Peer Review

- Reprints availability

- E-prints Service

- Manuscript Podcast for convenient understanding

- Global attainment for your research

- Manuscript accessibility in different formats

( Pdf, E-pub, Full Text, Audio)

- Unceasing customer service

Track the below URL for one-step submission https://juniperpublishers.com/online-submission.php 